\title{
Design Insights from the Implementation of a Student Result Processing System in Nigeria
}

\author{
Ifeanyi Glory Ndukwe* \\ University of Otago, New Zealand \\ E-mail: glory.ndukwe@otaco.ac.nz \\ Mmachi G. Obiorah \\ Northwestern University, Evanston, IL \\ E-mail: obiorahm@u.northwestern.edu
}

\begin{abstract}
The design of digital technologies is often influenced by the infrastructural, economic, and social realities of the environment of the designer. Thus, the Human Computer Interaction (HCI) community emphasize various strategies to learn from and about target users (Brown et al., 2010). However, products that are designed with the amount of detail recommended by the HCI community require a significant amount of time, energy and skill and as a result are expensive. The high cost of these services force individuals and organizations to resort to commercial products and it is often the case that commercial products that are successful for one group of people might be unsuitable for another (Johns et al., 2002). To address this problem, user groups often adapt the technology to suit their needs, use the technology in unintended ways or ultimately reject them. In this paper we present a case-study where locally developed technology was preferred over commercial solutions. We draw design insights from this experience on how we might design educational technologies while considering the culture of the target users.

Keywords: Education, Result computation in Higher Education, Educational Software Tools, Digital Tools in Higher Education
\end{abstract}

DOI: $10.7176 / \mathrm{DCS} / 9-8-05$

Publication date: August 31st 2019

\section{Introduction}

The Human-Computer Interaction (HCI) community is increasingly paying attention to the influence of different cultures on the way people engage with digital technologies (Blikstein, 2008; Cavallo, 2000; Horst et al., 2005; Huda, 2019). Digital technologies will not only be used to show how designers imagine that they will be used, users will adapt technologies to suit their particular context and their particular needs.

One of the great needs in the Nigerian education system is the security of student's results (Adebayo et al., 2014; Anujeonye, 2019). This is obviously a principal need for any educational system, however, the Nigerian context makes security a uniquely desirable feature. This is because of the prevalent corruption in many Nigerian institutions (Okolie et al., 2019; Yusuf et al., 2018). The corruption in Nigeria has been described as being systemic (Fry, 2018; Ijewereme, 2015). This means that corruption is woven into the very fabric of the nation in such a way that one cannot function in the system without engaging in corrupt practices (Altbach, 2005). In regards to students' results, it is not uncommon to find that documents containing students' results have been altered when they are passed on from the initial creator of the document to another person who assists in the student grade processing.

In many Nigerian institutions, digital technologies are welcomed as being means for eliminating corrupt practices that have prevailed as a result of human-to-human contact (Ejue et al., 2014; Mutungi et al., 2019; Salbu, 2001). However, we found that this was not the case with the particular university where we are conducting our study. The university's initial attempt to use digital technologies for student grade processing raised for more questions than resolved their fears for the stakeholders. This is because on initial introduction of digital technologies for students' grade processing, a secretary was given a paper version of student's results to enter into a digital spreadsheet and reproduce the results in a more readable format. This transfer from the course lecturer to the departmental secretary was a loophole in the system as it created opportunities for the students' grades to be changed or shared with unauthorized people before the grades were ready to be made available publicly. This experience has shaped the perception of the adoption of digital technologies for processing of students' results in the university we consider in this paper.

The evident question given this situation is - how do we tackle situations where digital technologies are not being accepted because they are perceived as avenues to further corrupt a system. In the remaining sections of this paper, we present a success story of adoption of digital solutions for processing student's grades in spite of an initial distasteful experience with digital technologies.

\section{Literature Review}

Technologies that are successful in developed countries are not always successful in developing countries (Sipe- 
Haesemeyer, 2005). Furthermore, even when digital technologies are successfully transferred, people from developing countries adapt technologies for their specific context that may not be consistent with the ways the technologies were designed to be used (Horst et al., 2005).

Many reasons have been identified as the cause of this disconnect. For instance, Blikstein (2008) reported that children in a South American school were unwilling to use high-tech technologies to learn because they were afraid that they would break them and they could not afford the replacement cost. The fear of having to pay the replacement cost stifled the children's creativity. Another reason for the lack of success of transferred digital technologies is that they are sometimes simply not feasible in low infrastructure communities because there is no physical infrastructure to support and maintain their use (Brewer et al., 2005).

Therias et al. (2015) recommended understanding the local context; using a bottom-up approach; involving stakeholders and empowering the communities as design values that can contribute to the successful integration of technologies in low infrastructure communities. We find that these values emerged in the design we deployed for processing of students' results. However, we identify other design values that were important for the successful deployment of our Electronic Senate Format Result (ESFR) software application in an environment where trust of the deployed system was key and infrastructure was low. We share these design values in other sections of this paper.

\section{Traditional Senate Format Results}

In the university where we are conducting our study, students are assessed as a group. Each student belongs to a level (100, 200, 300 or 400 level) and a lecturer who is known as the Level Coordinator (LC) is responsible for organizing and documenting academic activities related to that level. After the course lecturers' grades students' exams, their results are presented to the department, faculty and senate respectively for further assessment. If the results pass all the levels of assessment, they are then printed out and pasted on the department's notice board.

After a school session, the LC then collect all the grades for each course taken by all students in the particular level and then organizes them in a spreadsheet. This organization is typically done with Excel spreadsheets. This entry into Excel spreadsheets was done manually. Every student grade for every course the student has taken is entered into the spreadsheet cell by cell. This process is very tedious starting from collection of the grades from Course Lecturers to entering of the grades into the spreadsheet cell by cell. Collecting students' course grades involves walking to different departments where students have taken courses and picking up printed spreadsheets of students' results for that course. This course grade spreadsheet is different from what we will refer to as senate format from here on. The senate format spreadsheet contains the students' results from their first year to their current year and all the details a transcript typically has (these details are named in the section on e-Senate Format Results). This result is again assessed at the departmental, faculty and senate levels and when they are approved they become available to students. Each student contacts their LC in person and the content of the senate format is dictated to the student depending on what fields in the spreadsheet the LC feels is relevant to the student. The most gruesome part of coming up with this senate format is the number of times it has to be reformatted because of errors introduced by manual entry and formula entry into the spreadsheet. During the presentation of senate format results at the departmental, faculty and senate levels, errors are identified that range from technical errors to formatting errors and even to spelling errors. This method for presenting student results has been used for a very long time and to a great extent helped to organize the presentation of student grades.

\subsection{Other Proposed Digital Solutions}

The university in this study, has an online educational management system managed by its IT center that allows students to register their courses online. The system was introduced in 2002. Using this system, students have been able to pay their school fees remotely and online, apply for school housing and register 100 and 200 Level courses. The potential of this system however is tremendous as courses may be registered at every level; lecturer may enter student grades remotely; cumulative grade point averages may also be calculated and students can access details of their results as soon as the lecturers make them available. However, the capabilities of the online solutions have not taken advantage of for many reasons that we discuss throughout this paper.

Teaching staff in the university were resistant to this system because it was controlled by the IT center's personnel. The biggest fear expressed was that they did not trust the people who managed the center. Lecturers themselves, not being technical experts were worried that changes could be made in the system that they would not be able to recognize or track. Lecturers cited occurrences in the past where secretaries were given student results and some secretaries took advantage of the situation to exploit students and the system by receiving bribes for grade changes among other things. The above was the fear expressed by lecturers of the university but, in this paper, we identify other fears that we believe ESFR addressed and thus made it acceptable to the lecturers.

\section{2 e-Senate Format Results}

The main functional components of the ESFR include customizing the application to fit a particular use case, 
enrollment of students and computation of results (as illustrated in figure 1). Generally, ESFR comprises of five sections; Setup, File, Register, Result and Email. The Setup section consists of four sub sections; Grading System Setup, Department Setup, Faculty Setup and Course Setup (see figure 2). The Grading System setup is used to set up the Number of Semesters Attainable, Maximum Credit Units, Minimum Credit Units, and Total Credit Units required for a student to graduate. The Faculty, Department and Courses subsections are used to add, delete or update faculties, departments and courses. In addition, the Courses subsection can be used to add course prerequisites for a particular course code as well as set the maximum grade point required to pass that course.

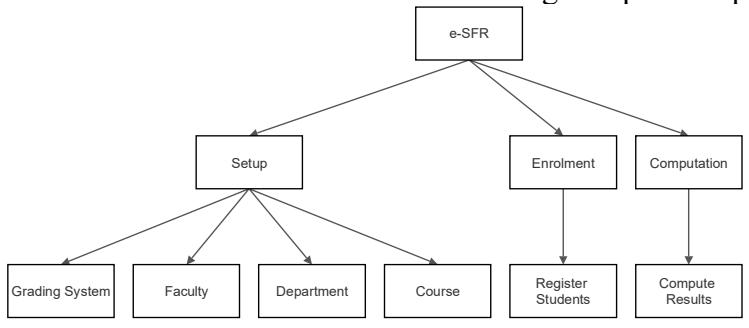

Figure 1. High-Level design of ESFR.

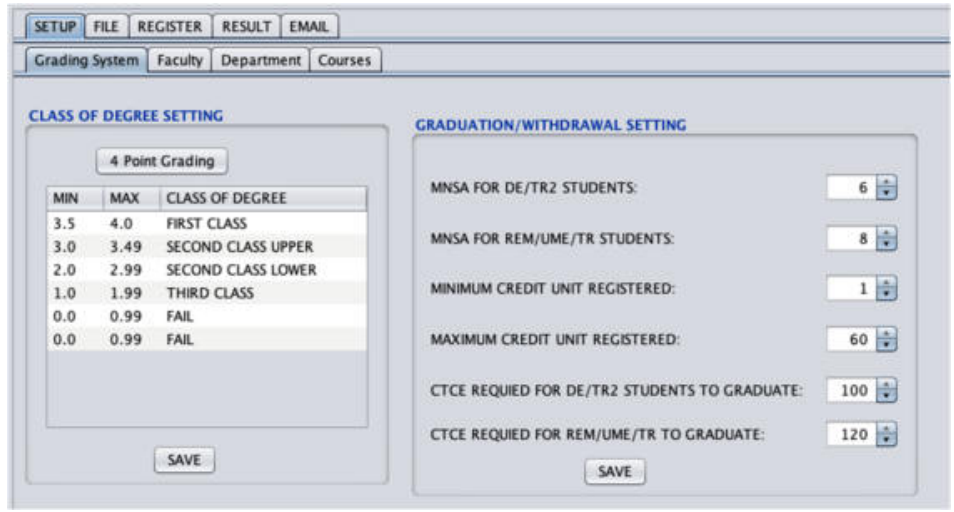

Figure 2. This page helps to set up the senate agreed upon template for student result presentation. It includes all the senate required fields.

The Register Section is used to enroll students for a new session. This section reduces the risk of enrolling students who are not eligible to register as a result of the course pre-requisite. This section also has a mechanism of detecting students that are not qualified to enroll for that session due to their withdrawal or invalid status (see figure 3).

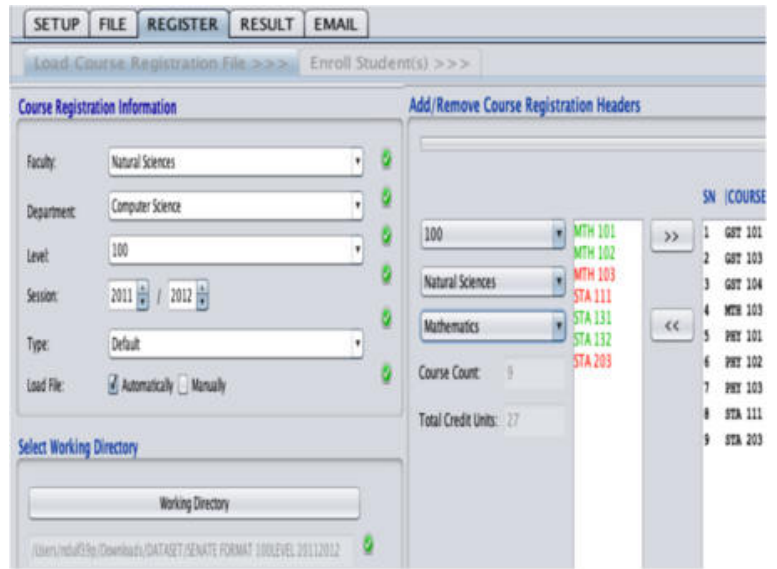

Figure 3. This page performs validate student data and also handles student registration and fulfillment of prerequisites.

The Result section computes the sessional result, which collates all course by course scores and grade points of each student and total all their Credit Units Registered, Credit Units Earned, Grade Points to actualize a student's Grade Point Average (GPA), Cumulative Total Credit Registered (CTCR), Total Cumulative Credit Earned (CTCE), Cumulative Total Grade Points (TGP) and Cumulative Grade Point Average (CGPA) (see figure 4). The File section is used to create and appropriately name course registration files and the results following a particular 
naming convention. Finally, the Email section is used to distribute copies of result to distinct students.

\begin{tabular}{|c|c|c|c|c|c|c|c|}
\hline SETUP & FLLE & REGISTER & RESULT [ & EMAIL & & & \\
\hline \multicolumn{4}{|c|}{ Load Course Registration File $\gg>$} & \multicolumn{4}{|c|}{ Enroll Student(s) $\gg>$ Compues Senafe formar Result $\gg>>$} \\
\hline \multicolumn{8}{|c|}{ Compute Senate Format Result } \\
\hline \multicolumn{2}{|c|}{ Add Course } & \multicolumn{3}{|c|}{ 4PT GRADING SHSTEM * } & \multicolumn{3}{|l|}{ xts -} \\
\hline \multicolumn{8}{|c|}{ Course Result Table } \\
\hline & & $\mathrm{S} / \mathrm{N}$ & LEVEL & & COURSE CODE & CREDIT UNIT & FLE NAME \\
\hline 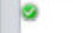 & 1 & & 100 & & STA203 & 4 & STA203_2011_2012.xis \\
\hline 0 & 2 & & 100 & & PHY103 & 3 & PHY103_2011_2012,xis \\
\hline$\Delta$ & 3 & & 100 & & МTH101 & 3 & MTH101_2011_2012.xts \\
\hline$\theta$ & 4 & & 100 & & Cst101 & 4 & CST101_2011_2012.xds \\
\hline e & 5 & & 100 & & STA111 & 4 & STA111_2011_2012.xis \\
\hline e & 6 & & 100 & & MTH102 & 3 & MTH102_2011_2012.xis \\
\hline
\end{tabular}

Figure 4. This page holds the final set of actions that create the senate form

The ESFR was built by a member of the Department of Computer Science in the university in this study. The tool was used by this department member who is a LC to compute the senate format for the level he coordinated. As a result of his speed and accuracy in generating results for the level he coordinated, other members of his department also used this tool. The success story spread to another department and workshops are currently being held to implement this tool as a university wide standard.

\section{Design Values Learned from ESFR}

4.1 Control of the System

Lecturers were distrustful of other sophisticated online solutions because the solutions seemed to take control away from the original owner of the senate format results. For instance, other proposed solutions required that the very first digital copy of the result be hosted on a server in the university's IT center. lecturers were distrustful of this system because it is shared similarities with a system that had been ineffective and corruptible (the one with the secretary intermediary). Lecturers were suspicious because they reasoned that the IT center was managed by humans other than themselves and these people could make changes to student grades without lecturers being aware of it.

On the other hand, ESFR is a standalone system before it is a networked system. The very first version of student's results is hosted on the lecturer's computer and then he/she is able to give others access to it as he/she wills. ESFR may not be more secure than other digital solutions that have been proposed but it enjoys acceptance by lecturers because they perceive it to be more secure. Lecturers feel that they have more control over students' results in a more tangible way.

\subsection{System Transparency}

The ESFR software is such that it is transparent to the user. Sometimes the workings of digital solutions seem magical. The users may be unable to trace how data flows in the system. When this is the case, users may reject the system depending on what they value. Other digital solutions have offered speed, accuracy and maybe even security but, lecturers were still suspicious of online digital solutions because they seemed to value security above all the advantages a digital online solution provided. Security may have meant to them being able to trace data and workflow in ways similar to the traditional system.

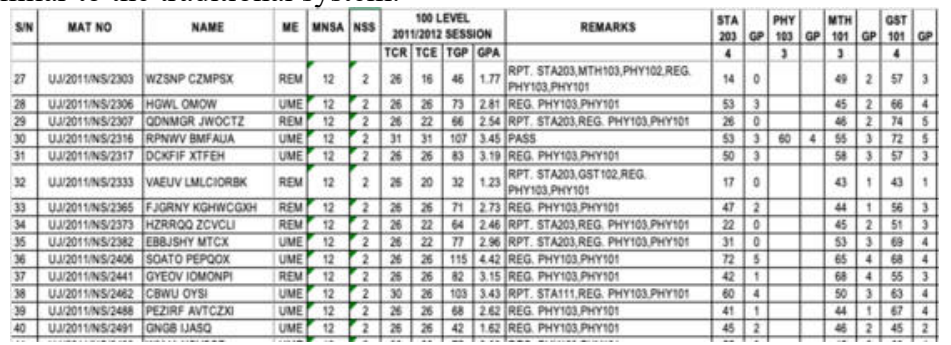

Figure 5. An example spreadsheet senate format result

In figure 5, it is evident that the traditional method matches a lot of the actions described in the ESFR section. Lecturers understood these actions and could relate to them. They can also make recommendations for improvement and point out loop holes. Other proposed solution did not consider that lecturers would have to make too sharp a shift from what they were used to. The new solutions did not address their problems it proposed a new 
way of working; new names to refer to things that they had known by other names.

Other proposed solutions may have produced students' results, but many times the solution produced results in ways that were not recognizable to the users, lecturers were interested in understanding how the digital solution mapped to their traditional way of working. When they could not see this relationship, they rejected the newly proposed systems.

\subsection{Infrastructural Needs}

Digital solutions are supported by infrastructure. Existing infrastructure determines what is possible digitally. Nigeria suffers from unstable electricity and Internet facilities. This means that systems that are heavily dependent on electricity and the Internet may be perceived as being bad solutions. Previous digital solutions were quite dependent on the availability of electricity and Internet connection. This made such solutions distasteful.

The labor required in the result processing by the ESFR is reduced to a very great degree even as a standalone solution. Furthermore, a network component is fused into the software that further reduces this labor. The standalone capabilities plus the networked capability also distributes the points of failure. The system can still function even when there is no electricity or Internet connection at the IT center of the university.

\subsection{Local Intelligence About the Needs of Nigerian Teachers}

The designers of this system, being lecturers in a Nigerian university, were making the ESFR solution for themselves first and foremost before they were making it for others. The system addressed their own needs and challenges as lecturers who process students' results. Being a part of the Nigerian education system, meant that the lecturers had local intelligence about the problems and needs of the result processing system. The designers understood the costs of transfer to a new system, they understood the biggest problems for lecturers and maybe most importantly, they were able to test their proposed system on their own result processing. This advantage of being able to test gave them an edge over other proposed digital solutions as they could demonstrating that the system worked by simply using it themselves. External designers would need to win lecturers over and have a lecturer champion their cause which is usually more difficult.

\subsection{Cost of Transfer}

Usually, new digital solutions are expensive. The solution may require purchasing new equipment; setting up new infrastructure; cost of training and many other unanticipated costs. These funds to implement these new solutions are also usually not immediately available. This stifles the implementation of new digital solution.

Our solution has the advantage that it grew organically out of the existing system. Our result processing system did not need a grant to be implemented or an external team of designers and developers to maintain the system. Rather, the system grew out of an authentic need. ESFR also grew out of existing infrastructure. We think that this is the best way for solutions to emerge as they are then more sustainable when they are built locally because the skill to maintain the solution is locally available. Local solutions also provide learning opportunities for residents of the community.

\section{Conclusion}

We have identified features of a result processing system that made it adoptable and successful in a Nigerian university setting. We believe that these features and considerations will be useful when designing solutions for developing countries. The design values we have shared here attempt to contribute to existing body of work for designing digital solutions for developing countries especially where corruption and lack of infrastructure are deterrents to the adoption of a digital solution. Recognizing that the human factor is one of the most influential in human-computer interaction and has led to increased growth in the software industry. The need for software projects to be developed such that they are of good quality and user-friendly is of paramount significance. In the future, we will collect data to explore the usability and usefulness of ESFR and to investigate the users (level coordinators) perception of the tool. We will analyze this data quantitatively and qualitatively.

\section{References}

Adebayo, O., \& Abdulhamid, S. M. (2014). E-exams system for Nigerian universities with emphasis on security and result integrity. arXiv preprint arXiv:1402.0921.

Altbach, P. (2005). Academic corruption: The continuing challenge. International Higher Education(38).

Anujeonye, C. N. (2019). PERCEPTION OF LECTURERS ON THE USE OF COMPUTER BASED TEST (CBT) IN NIGERIAN PUBLIC UNIVERSITIES. ONLINE JOURNAL OF ARTS, MANAGEMENT \& SOCIAL SCIENCES, 4(1).

Blikstein, P. (2008). Travels in Troy with Freire: Technology as an agent of emancipation. In Social Justice Education for Teachers (pp. 205-235): Brill Sense.

Brewer, E., Demmer, M., Du, B., Ho, M., Kam, M., Nedevschi, S., . . Fall, K. (2005). The case for technology in 
developing regions. Computer, 38(6), 25-38.

Brown, T., \& Wyatt, J. (2010). Design thinking for social innovation. Development Outreach, 12(1), 29-43.

Cavallo, D. (2000). Emergent design and learning environments: Building on indigenous knowledge. IBM Systems Journal, 39(3.4), 768-781.

Ejue, E. A., \& Madubueze, M. (2014). Corruption and service delivery in Local Government System in Nigeria: A content analysis. International Journal of Business and Social Science, 10(1), 97-107.

Fry, L. J. (2018). Perceptions of Corruption in Nigeria as a Barrier to Future Development. Asian Journal of Sociological Research, 10-20.

Horst, H., Miller, D., AustinBroos, D., Bauer, E., Carrier, J., Chevannes, B., . . Slater, D. (2005). From kinship to link-up: Cell phones and social networking in Jamaica. Current Anthropology, 46(5), 755-778.

Huda, M. (2019). Empowering application strategy in the technology adoption: insights from professional and ethical engagement. Journal of Science and Technology Policy Management, 10(1), 172-192.

Ijewereme, O. B. (2015). Anatomy of corruption in the Nigerian public sector: Theoretical perspectives and some empirical explanations. Sage Open, 5(2), 2158244015581188.

Johns, S. K., Smith, M., \& Norman, C. S. (2002). How culture affects the use of information technology. Paper presented at the Accounting Forum.

Mutungi, F., Baguma, R., \& Janowski, T. (2019). Towards Digital Anti-Corruption Typology for Public Service Delivery. Paper presented at the 20th Annual International Conference on Digital Government Research.

Okolie, U. C., Nwosu, H. E., Eneje, B. C., \& Oluka, B. N. (2019). Reclaiming education: Rising above examination malpractices, and its contextual factors on study progress in Nigeria. International Journal of Educational Development, 65, 44-56.

Salbu, S. R. (2001). Information technology in the war against international bribery and corruption: The next frontier of institutional reform. Harv. J. on Legis., 38, 67.

Sipe-Haesemeyer, M. A. (2005). Bringing the World Wide Web into Third World Countries: Integrating Technology Across the Globe. Global Media Journal, 4(7).

Therias, E., Bird, J., \& Marshall, P. (2015). Más tecnologia, más cambio?: Investigating an educational technology project in rural peru. Paper presented at the Proceedings of the 33rd Annual ACM Conference on Human Factors in Computing Systems.

Yusuf, A., Bello, M. B., Ayub, A., \& Balogun, I. N. (2018). Teachers' Perception of Civic Education as a Measure of Curbing Corruption in Nigeria. KIU Journal of Humanities, 3(1), 61-68. 